\title{
Load Frequency Control in Deregulated Power System using Fuzzy C-Means
}

\author{
S. Srikanth \\ BVC Engineering College \\ Department of EEE \\ Odalarevu, A.P,India
}

\author{
K.R. Sudha \\ A.U College of Engineering \\ Andhra University \\ Visakhapatnam, A.P, India
}

\author{
Y.Butchi Raju \\ Sir CRR College of Engineering \\ Department of EEE \\ Eluru, AP,India
}

\begin{abstract}
In this paper, a fuzzy C-means controller proposed to the generation of optimal fuzzy rule base by Fuzzy C - Means clustering technique (FCM) for load frequency control in deregulated environment. The phase-plane plot of the inputs of the fuzzy controller is utilized to obtain the rule-base in the linguistic form. The proposed method is tested on a two-area power system with different contracted scenarios under various operating conditions. The results of the proposed controller are compared with the fuzzy PID controller and conventional PID controller to illustrate its robust performance. These comparisons demonstrate the superiority and robustness of the proposed controller.
\end{abstract}

\section{Keywords}

LFC, Fuzzy PID Controller, Fuzzy C-means Controller, Deregulated Environment.

\section{INTRODUCTION}

In the power system, any sudden load change causes the deviation of frequency and tie-line power. So, that Load Frequency Control (LFC) is a very important issue in power system operation and control for supplying sufficient and reliable electric power with good quality [19]. The main aim of the LFC is to maintain zero steady state errors for frequency deviation and Tie-line power in a multi-area restructured power system. A lot of studies have been made in the last two decades about the LFC in interconnected power systems [1-7]. In most of the researchers Proportional Integral (PI) controllers have been widely used for decades as the load frequency controllers. Actually, several techniques have been proposed to design the PI controller, where the controller parameters of the PI controller are tuned using trial-and-error approach. However, it gives poor performance in the system transient response. Proportional Integral Derivative (PID) controller has been proposed to improve the performance of load frequency control problem. the mentioned technique needs to a more complex design process [10]. The real world power system contains different kinds of uncertainties due to load variations, system modeling errors and change of the power system structure. Many authors have proposed fuzzy logic based controllers to power systems [9][12][14]. Fuzzy logic is a rule-based approach to decision making. This approach is used to handle imprecise knowledge and was developed in the sixties by H. Shayeghi [15]. Such knowledge can be collected and delivered by a human expert (e.g. decision-maker, designer, process planner, machine operator, etc.). Fuzzy C-Means (FCM) is a Clustering algorithms permit the classification of the data in distinct groups using distance and/or similarity functions. These groups can later be used directly in selecting appropriate fuzzy set boundaries. Also the algorithms can automatically combine similar objects (data entries) in order to reduce the global size of the data. Finally the clustering algorithms let us easily detect potential outliers (clusters containing one or very few data entries). This feature is taken into consideration to design a decentralized fuzzy controller. The phase plane plot of the input space is formed into clusters with the cluster centers is formed to obtain the required rule-base of the proposed fuzzy controller[22].The proposed control has simple structure and does not require an accurate model of the plant. Thus, its construction and implementation are fairly easy and can be useful for the real world complex power system. The proposed method is applied to a two-area restructured power system as a test system. The results of the proposed Fuzzy-C-means controller are compared with the Fuzzy PID (FPID) controller [18] and conventional PID controller [9] through some performance indices in the presence of large parametric uncertainties and system nonlinearities under various area load changes

\section{DEREGULATED POWER SYSTEM FOR LFC WITH TWO AREAS}

Simultaneous design for a fixed controller structure is used in all reported decentralized LFC scenarios. This approach is numerically difficult for a large scale power system. Traditionally, electric industry is vertically integrated with all the transmission, generation and distribution under its control with interconnecting with the neighboring areas[11]. Whereas, in deregulated power systems, the Vertically Integrated Utility (VIU) no longer exists [4]. However, the usual LFC objectives, i.e. reconstruction the frequency and the net interchanges to their ideal values for each control area, still remain. For the purpose of evaluating the performance of such a system, a flexible technique has been developed and implemented. The method assumes that LFC is performed by an Independent System Operator (ISO) based on parameters defined by the participating generating units [1]. The participant units comprise beneficial generators and independent power producers. The utilities describe the units, which will be under LFC, while the independent power producers may or may not participate in the load frequency control [3]. Deregulated system will consist of GENCOs, DISCOs, and transmission companies (TRANSCOs) and independent system operator (ISO). However,the common AGC goals i.e., restoring the frequency and the net interchanges to their desired values for each control area [17]. The power system is assumed to contain two areas and each 


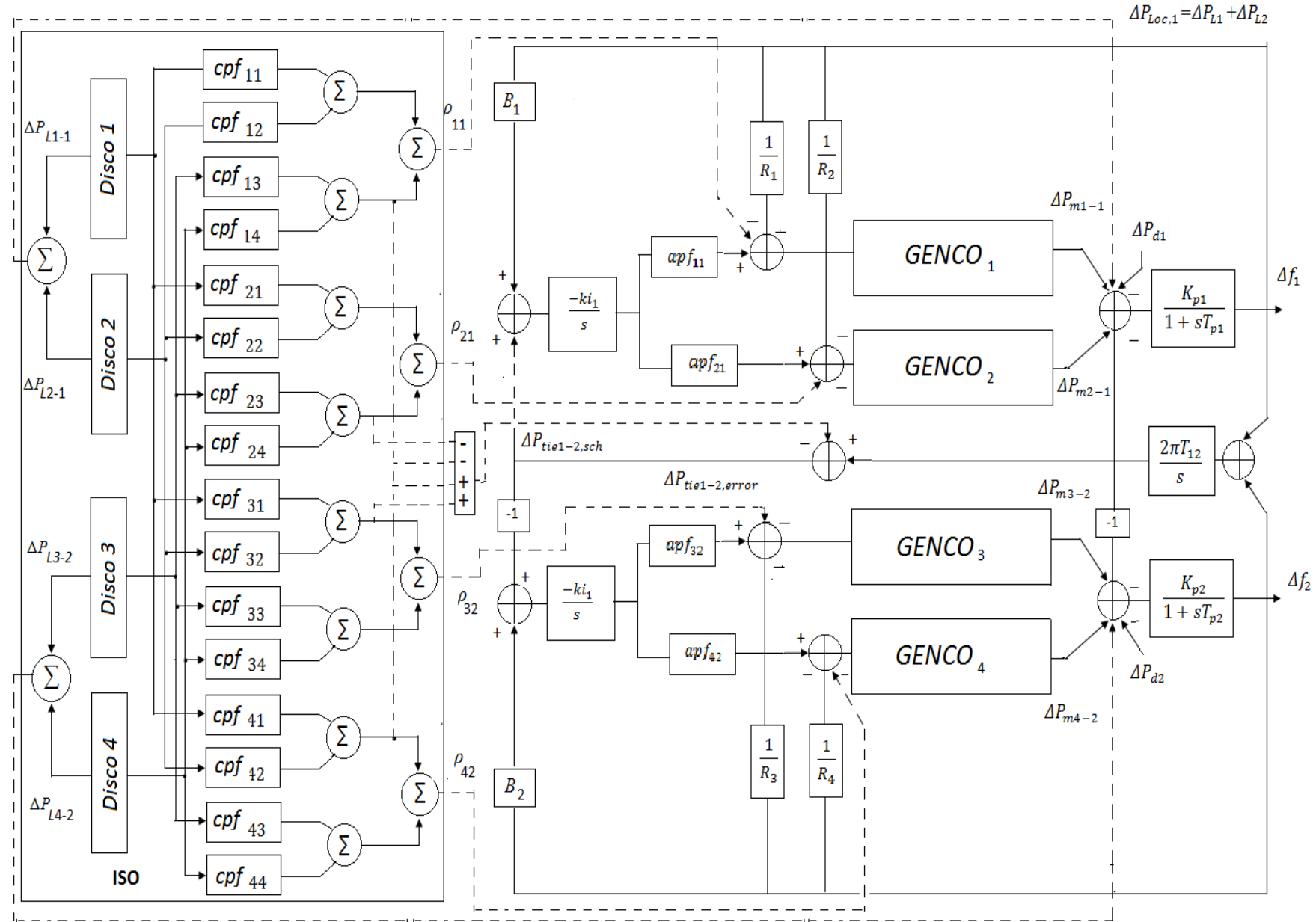

Figure1 Block diagram of two-area power system in deregulated environment

area includes two GENCOs and also two DISCOs and the block diagram of the generalized LFC scheme for a two area deregulated power system is shown in fig.1. A DISCO can contract individually with any GENCO for power and these transactions are made under the super vision of ISO. To make the visualization of contracts is the concept of a 'DISCO participation matrix' (DPM) will be used [2]. Essentially, DPM gives the participation of a DISCO in contract with a GENCO. In DPM, the number of rows has to be equal to the number of GENCOs and the number of columns has to be equal to the number of DISCOs in the system. Any entry of this matrix is a fraction of total load power contracted by a DISCO toward a GENCO. As a result total of entries of column belong to DISCO of DPM is

$\Sigma \mathrm{i}$ Cpfij=1. The corresponding DPM for the considered power system having two areas and each of them including two DISCOs and two GENCOs is given as follows:

\section{Where}

$\operatorname{cpf}_{\mathrm{ij}}=\frac{\mathrm{j}^{\text {th }} \text { DISCO power demand out of } \mathrm{i}^{\text {th }} \text { GENCO in p.uMW }}{\mathrm{j}^{\text {th }} \text { DISCO total power demand in p.uMW }}$

$\mathrm{DPM}=\left[\begin{array}{llll}c p f_{11} & c p f_{12} & c p f_{13} & c p f_{14} \\ c p f_{21} & c p f_{22} & c p f_{23} & c p f_{24} \\ c p f_{31} & c p f_{32} & c p f_{33} & c p f_{34} \\ c p f_{41} & c p f_{42} & c p f_{43} & c p f_{44}\end{array}\right]$
Where Contract participation factor (CPF)is like a signal that carry information as to which GENCO has to follow load demanded by which DISCO. The actual and scheduled steady state power flows on the tie line are given as:

$\Delta P_{\text {tieij }}($ scheduled $)=$

$$
\text { (demand of DISCO in } \mathrm{j}^{\text {th }} \text { area from GENCO in } \mathrm{i}^{\text {th }} \text { area) }
$$

$-\left(\right.$ demand of DISCO in $\mathrm{i}^{\text {th }}$ area from GENCO in $\mathrm{j}^{\text {th }}$ area $)$

And at any given time, the tie line power error $\Delta$ Ptie1-2, error is defined as

$\Delta \mathrm{P}$ tie1-2, error $=\Delta \mathrm{P}$ tie1-2, actual $-\Delta \mathrm{P}$ tie1-2, scheduled

The error signal is used to generate the respective ACE signals as in the traditional scenario.

$$
\begin{aligned}
& \mathrm{ACE} 1=\mathrm{B} \Delta \mathrm{f} 1+\Delta \mathrm{P} \text { tie1-2,error } \\
& \mathrm{ACE} 2=\mathrm{B} \Delta \mathrm{f} 2+\Delta \mathrm{P} \text { tie2-1,error }
\end{aligned}
$$

The closed loop system in fig. 2 is characterized in state space form as

A fully controllable and observable, dynamic model for a two area power system is proposed, where ' $x$ ' is the state vector and ' $u$ ' is the vector of power demands of the DISCOs. 
The deviation of frequency, turbine output and tie-line power flow within each control area are measurable outputs that can be used for output feedback.

The doted and dashed lines show the demand signals based on the possible contracts between GENCOs and DISCOs that carry information as to which GENCO has to follow a load demanded by that DISCO. These new information signals where absent in the traditional LFC scheme. As there are many GENCOs in each area, the ACE signals have to be distributed among them due to their ACE participation factor in LFC[16].

\section{FUZZY C-MEANS CLUSTERING ANALYASIS}

In recent years, fuzzy modeling technique have become an active research area due to its successful application to complex system model, where classical methods such as mathematical and model-free methods are difficult to apply because of lack of sufficient knowledge. The Fuzzy Logic model is empiricallybased, relying on an operator's experience rather than their technical understanding of the system. For a little more complex system, but for which significant data exist, model free method such as neural networks provide a powerful and robust means to reduce some uncertainty through learning, based on patterns in the available data. For the most complex system where few numerical data exist and only ambiguous or imprecise information may be available, fuzzy reasoning provides a way to understand system behavior by allowing us to interpolate approximately between observed input and output situation[24].The imprecision in fuzzy models is therefore, generally quite high. Fuzzy systems can implement crisp input and output, and produce a non-linear functional mapping just as do algorithms [14, 21]. Depending on the system, it may not be necessary to evaluate every possible input combination since some may rarely or never occur. This will increase the number of fuzzy rules and complexity but may also increase the quality of the control. Fuzzy C-Means (FCM) is a method of clustering which allows one piece of data to belong to two or more clusters $[23,25]$. This is frequently used in pattern recognition. It is based on minimization of the following objective function:

$J_{m}=\sum_{i=1}^{N} \sum_{j=1}^{C} u_{i j}^{m}\left\|x_{i}-c_{j}\right\|^{2}$

where $\mathrm{m}$ is any real number greater than 1 , uij is the degree of membership of $x i$ in the cluster $j$, $x i$ is the ith of d-dimensional measured data, cj is the d-dimension center of the cluster, and $\|*\|$ is any norm expressing the similarity between any measured data and the center.

Fuzzy partitioning is carried out through an iterative optimization of the objective function shown above, with the update of membership uij and the cluster centers cj by:

$$
u_{i j}=\frac{1}{\sum_{k=1}^{c}\left(\frac{\left\|x_{i}-c_{j}\right\|}{\left\|x_{i}-c_{k}\right\|}\right)^{\frac{2}{m-1}}}
$$

Where

$$
c_{j}=\frac{\sum_{i=1}^{N} u_{i j}^{m} x_{i}}{\sum_{i=1}^{N} u_{i j}^{m}}
$$

where $\epsilon$ is a termination criterion between 0 and 1 , where as $\mathrm{k}$ are the iteration steps. This procedure converges to a local minimum or a saddle point of $\mathrm{Jm}$

In a batch mode operation, FCM determines the cluster centers ci and the membership matrix $U$ using the following steps:

Step 1: Set the number of clusters c Initialize the membership matrix $U$ with random values between 0 and 1 such that the summation of degrees of belongingness of a data point to all clusters is always equal to unity.

Step 2: Calculate c Fuzzy cluster centers, 1, ci where i $=1$, $2, \ldots$ c, using Eq. (9).

Step 3: Compute the objective function according to Eq. (8). Stop if either it is below a certain tolerance value or its improvement over previous iteration is below a certain threshold.

Step 4: Compute a new U using Eq. (9). Go to Step 2.

\section{DESIGN OF PROPOSED FUZZY CONTROLLER USING FUZZY C-MEAN ALGORITHM (FCM CONTROLLER)}

The Normal Fuzzy controller is designed heuristically with rules as shown in Table 2. The structure of the Fuzzy Controller is as shown in the Fig.(3).

The three normalized input variables $\delta, \dot{\delta}, \ddot{\delta}$ are first fuzzified

The definitions of the fuzzy sets are as follows [10-12]:

$$
\begin{aligned}
& \mu_{Z}(.)=\left(\begin{array}{l}
{[x(.)+1] \quad \text { if } x(.) \in[-1,0]} \\
-[x(.)-1] \text { if } x(.) \in[0,1]
\end{array}\right. \\
& \mu_{P}(.)=x(.) \text { if } x(.) \in[0,1] \\
& \mu_{N}(.)=-x(.) \text { if } x(.) \in[-1,0]
\end{aligned}
$$

The Fuzzy C-Means controller is tuned to the normal fuzzy controller. The phase-plane plot of the input space is obtained. The input space is divided into clusters and the cluster centers are identified. The sequence of rules of the original fuzzy controller are super imposed onto the phase-plane plot of the input space with cluster centers as shown in Fig.4 . Hence, the required rules are identified and the non-cooperative rules are eliminated as shown in Table-2

The efficacy of the proposed method is demonstrated for load frequency control of two-area in deregulated Power system. The performance of the proposed controller is compared with conventional controller, original fuzzy controller in Table -1

This iteration will stop when $\left\{\left|u_{i j}^{(k+1)}-u_{i j}^{k}\right|\right\}<\epsilon$ 
Table 1 Representation of rules in linguistic form

\begin{tabular}{|c|c|c|}
\hline Rule-1 & $\begin{array}{l}\text { If } X(\dot{\delta}) \text { is } \mathrm{P} \text { and } \\
\text { then output is } \mathrm{NB}\end{array}$ & is $\mathrm{P}$ and $X(\ddot{\delta})$ is $\mathrm{P}$ \\
\hline Rule-2 & $\begin{array}{l}\text { If } X(\dot{\delta})_{\text {is P and }} x(\delta) \\
\text { then output is NS }\end{array}$ & is $\mathrm{P}$ and $X(\ddot{\delta})$ is $\mathrm{N}$ \\
\hline Rule-3 & $\begin{array}{l}\text { If } X(\dot{\delta}) \text { is } \mathrm{P} \text { and } \\
\text { then output is } \mathrm{NM}\end{array}$ & is $\mathrm{P}$ and $X(\ddot{\delta})$ is $\mathrm{Z}$ \\
\hline Rule-4 & $\begin{array}{l}\text { If } X(\dot{\delta})_{\text {is } \mathrm{P} \text { and }} x(\delta) \\
\text { then output is NM }\end{array}$ & is $\mathrm{N}$ and $X(\ddot{\delta})$ is $\mathrm{P}$ \\
\hline Rule-5 & $\begin{array}{l}\text { If } X(\dot{\delta}) \text { is } \mathrm{P} \text { and } \\
\text { then output is } \mathrm{Z}\end{array}$ & is $\mathrm{N}$ and $X(\ddot{\delta})$ is $\mathrm{Z}$ \\
\hline Rule-6 & $\begin{array}{l}\text { If } X(\dot{\delta}) \text { is P and } x(\delta) \\
\text { then output is NS }\end{array}$ & is $\mathrm{N}$ and $X(\ddot{\delta})$ is N \\
\hline Rule-7 & $\begin{array}{l}\text { If } X(\dot{\delta})_{\text {is } \mathrm{P} \text { and }} x(\delta) \\
\text { then output is } \mathrm{NM}\end{array}$ & is $\mathrm{Z}$ and $X(\ddot{\delta})$ is $\mathrm{P}$ \\
\hline Rule- 8 & $\begin{array}{l}\text { If } X(\dot{\delta})_{\text {is } \mathrm{P} \text { and }} x(\delta) \\
\text { then output is NS }\end{array}$ & is $\mathrm{Z}$ and $X(\ddot{\delta})$ is $\mathrm{Z}$ \\
\hline Rule-9 & $\begin{array}{l}\text { If } X(\dot{\delta}) \text { is } \mathrm{P} \text { and } \\
\text { then output is } \mathrm{Z}\end{array}$ & is $\mathrm{Z}$ and $X(\ddot{\delta})$ is $\mathrm{N}$ \\
\hline Rule-10 & $\begin{array}{l}\text { If } X(\dot{\delta}) \text { is N and } x(\delta) \\
\text { then output is } \mathrm{NM}\end{array}$ & is $\mathrm{P}$ and $X(\ddot{\delta})$ is $\mathrm{P}$ \\
\hline Rule-11 & $\begin{array}{l}\text { If } X(\dot{\delta}) \text { is } \mathrm{N} \text { and } \\
\text { then output is } \mathrm{Z}\end{array}$ & is $\mathrm{P}$ and $X(\ddot{\delta})$ is $\mathrm{Z}$ \\
\hline Rule-12 & $\begin{array}{l}\text { If } X(\dot{\delta}) \text { is } \mathrm{N} \text { and } x(\delta) \\
\text { then output is PS }\end{array}$ & is $\mathrm{P}$ and $X(\ddot{\delta})$ is $\mathrm{N}$ \\
\hline
\end{tabular}

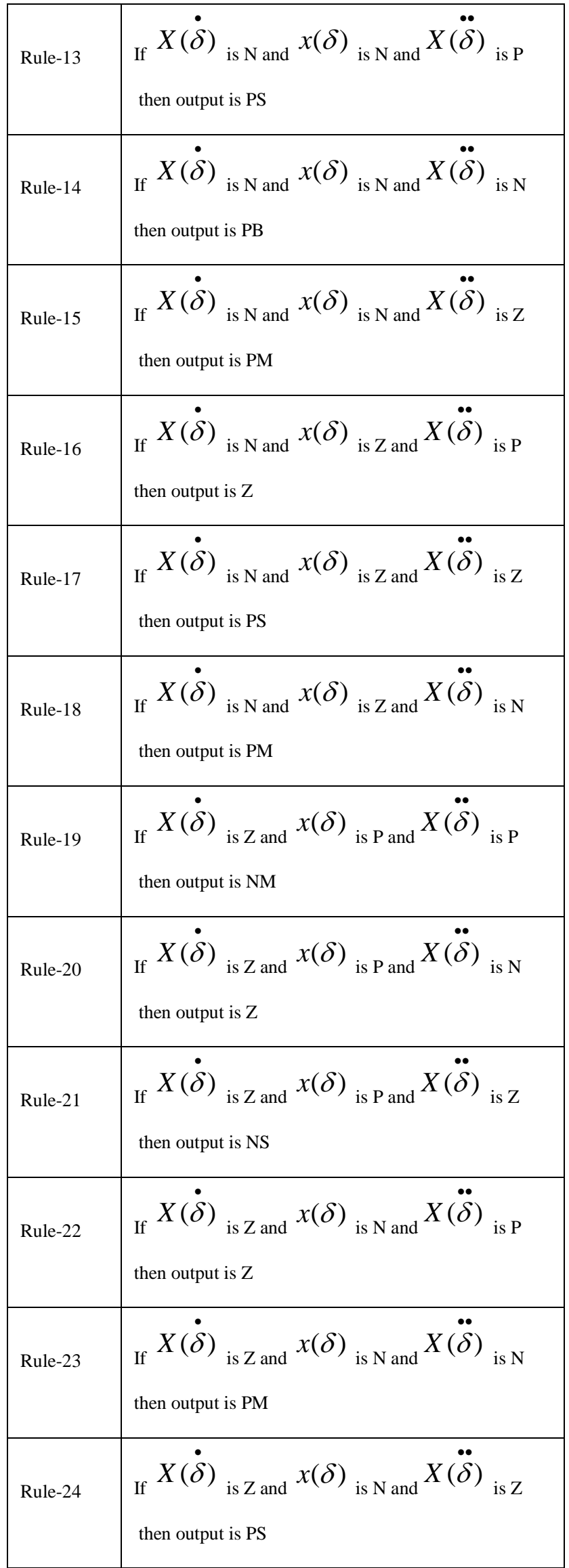




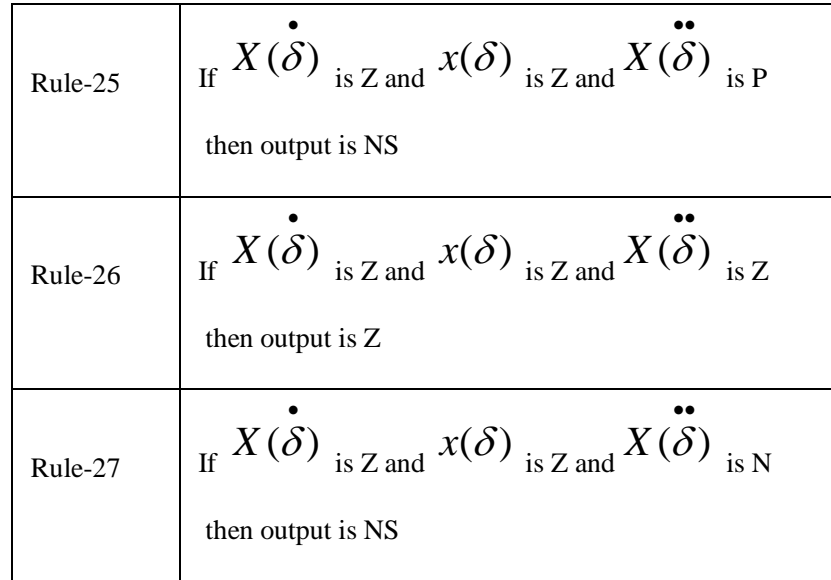

Table 2 Representation of rules in linguistic form

\begin{tabular}{|c|c|}
\hline Rule -17 & $\begin{array}{l}\text { If } X(\dot{\delta}) \text { is } \mathrm{N} \text { and } \\
\text { then output is PS }\end{array}$ \\
\hline Rule -18 & $\begin{array}{l}\text { If } X(\dot{\delta})_{\text {is } \mathrm{N} \text { and }} x(\delta) \text { is } \mathrm{Z} \text { and } \\
\text { then output is } \mathrm{PM}\end{array}$ \\
\hline Rule -21 & $\begin{array}{l}\text { If } X(\dot{\delta}) \text { is Z and } x(\delta) \text { is } \mathrm{P} \text { and } X(\dot{\delta}) \text { is } \mathrm{Z} \\
\text { then output is NS }\end{array}$ \\
\hline Rule -25 & $\begin{array}{l}\text { If } X(\dot{\delta})_{\text {is } \mathrm{Z} \text { and }} x(\delta) \text { is } \mathrm{Z} \text { and } \\
\text { then output is } \mathrm{NS}\end{array}$ \\
\hline Rule -26 & $\begin{array}{l}\text { If } X(\dot{\delta}) \text { is } \mathrm{Z} \text { and } \\
\text { then output is } \mathrm{Z}\end{array}$ \\
\hline
\end{tabular}

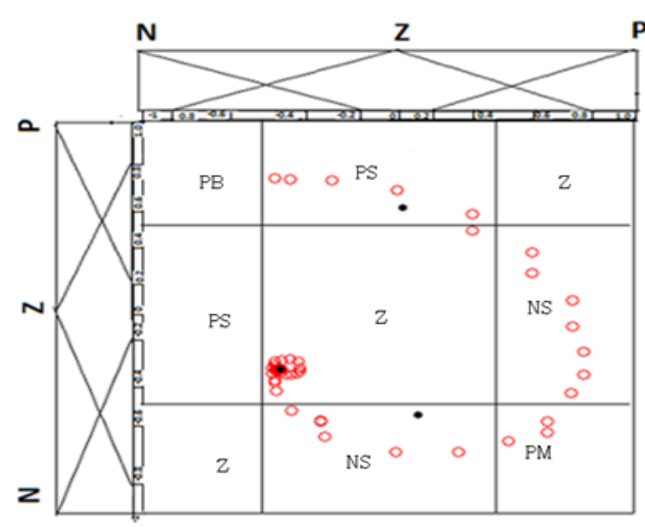

Fig 2. Phase-plane plot of the input space with cluster centers

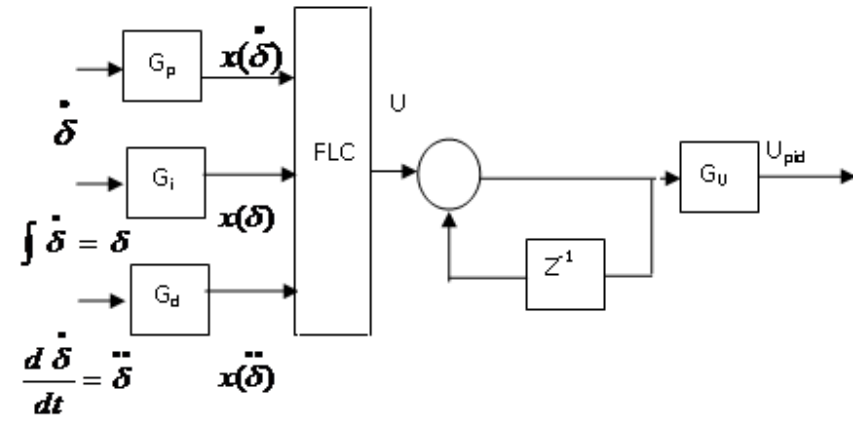

Fig 3. Schematic diagram of FLPSS

\section{SIMULATION RESULTS}

To illustrate the performance and robustness of the proposed control against parametric uncertainties and unconstructed

loads variations, simulations are performed for three scenarios of possible contracts under various operating conditions and large load demands

A Scenario 1: transaction based on free contracts:

In this scenario, DISCOs have the freedom to have a contract with any GENCO in their or other areas. So all the DISCOs contract with the GENCOs for the power based on following $\mathrm{DPM}=\left[\begin{array}{cccc}0.5 & 0.25 & 0 & 0.3 \\ 0.2 & 0.25 & 0 & 0 \\ 0 & 0.25 & 1 & 0.7 \\ 0.3 & 0.25 & 0 & 0\end{array}\right]$

It is considered that each DISCO demands 0.1 pu total power from GENCOs as defined by entries in DPM and each GENCO participates in AGC as defined by the following apf:

$$
\begin{array}{ll}
a p f_{11}=0.75 & \operatorname{apf}_{21}=1-a p f_{11}=0.25 \\
a p f_{32}=0.5 & a p f_{42}=1-a p f_{32}=0.5
\end{array}
$$

The results for this Scenario are given in Fig8-10

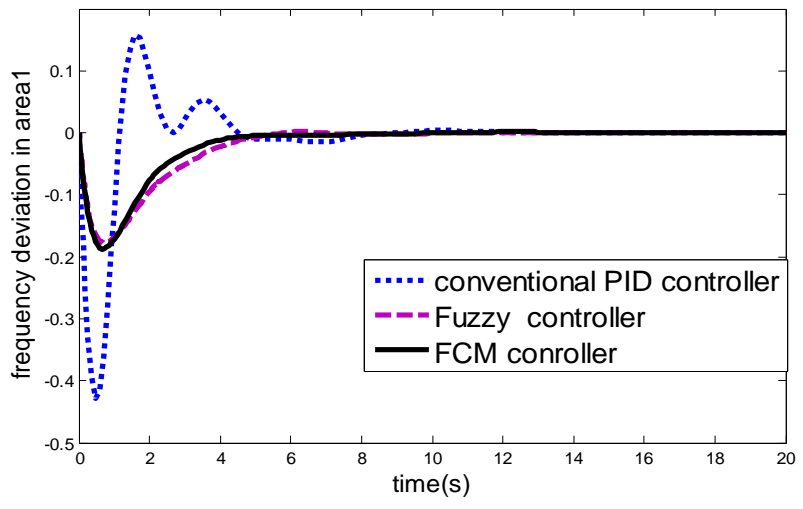

Fig4. Freqency deviation in area1 $(\mathrm{rad} / \mathrm{sec})$ 


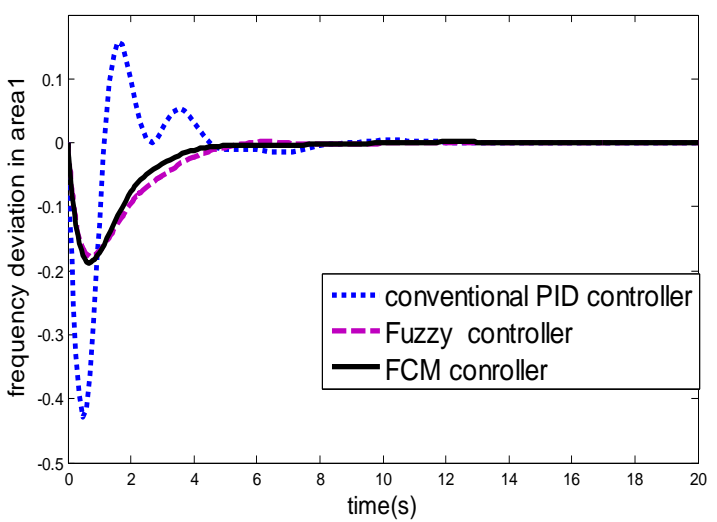

Fig5. Freqency deviation in $\operatorname{area2}(\mathrm{rad} / \mathrm{sec})$

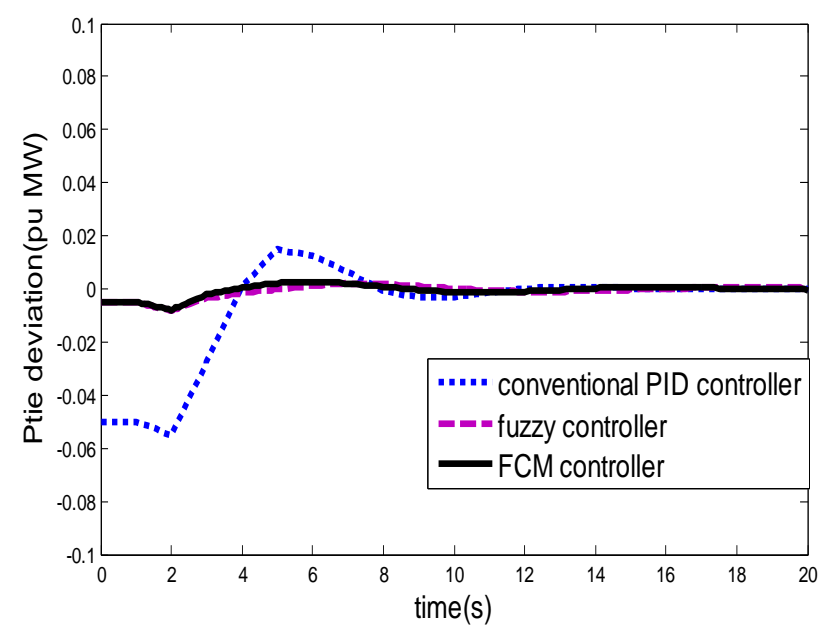

Fig6. Tie line power deviation(pu/MW)

B Scenario 2: transaction based on free contracts no violation

In this scenario, DISCOs have the freedom to have a contract with any GENCO in their or other areas. So all the DISCOs contract with the GENCOs for the power based on following

$$
\mathrm{DPM}=\left[\begin{array}{cccc}
0.5 & 0.25 & 0 & 0.3 \\
0 & 0 & 0 & 0 \\
0 & 0.5 & 1 & 0.7 \\
0.5 & 0.25 & 0 & 0
\end{array} \mid\right.
$$

It is considered that each DISCO demands $0.1 \mathrm{pu}$ total power from GENCOs as defined by entries in DPM and each GENCO participates in AGC as defined by the following apf:

$$
\begin{array}{ll}
a p f_{11}=0.75 & a p f_{21}=1-a p f_{11}=0.25 \\
a p f_{32}=0.5 & a p f_{42}=1-a p f_{32}=0.5
\end{array}
$$

The results for this Scenario are given in Fig11-13

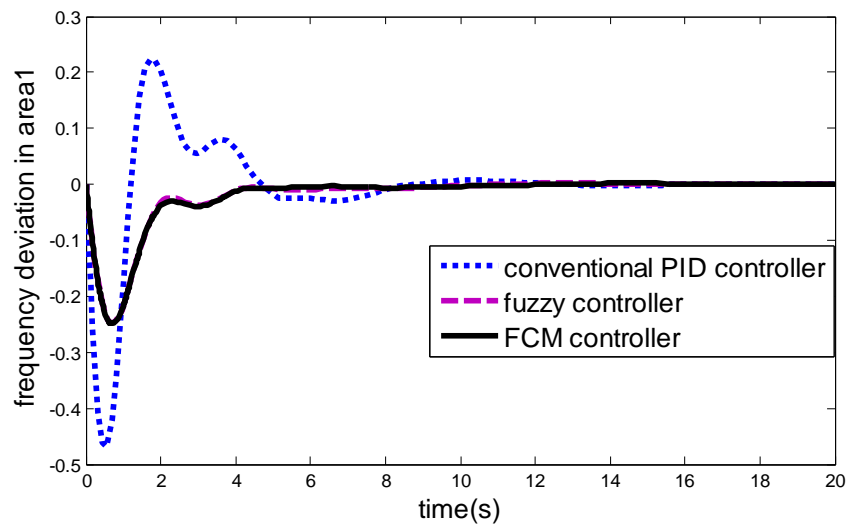

Fig7. Freqency deviation in $\operatorname{area} 1(\mathrm{rad} / \mathrm{sec})$

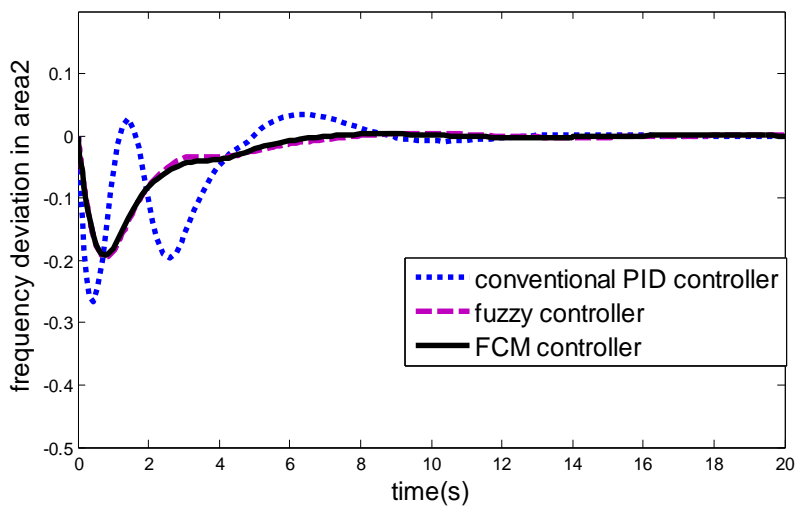

Fig8. Freqency deviation in area2(rad/sec)

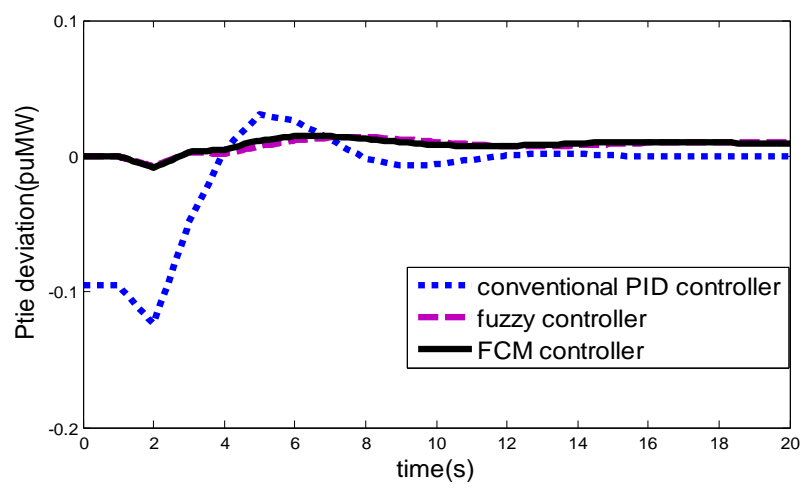

Fig9. Tie line power deviation(pu/MW)

C. Scenario 3: contract violation

In this case, the DISCOs may violate a contract by demanding more or less power than that specified in the contract. This excess power is reflected as a local load of the area (unconstructed demand). In this section it is assumed that in addition to the specified contracted load demands DISCO in area 1 , demand 0.1 p.u as large unconstructed load in each area is taken up by the GENCOs in the same area and the tie line powers are the same as in scenario 1 in the steady state. The purpose of this scenario is to test the effectiveness of the proposed controller against uncertainties and large load disturbances $\Delta \mathrm{Pd}$ 
The power based on following DPM:

$$
\mathrm{DPM}=\left[\begin{array}{cccc}
0.5 & 0.25 & 0 & 0.3 \\
0.2 & 0.25 & 0 & 0 \\
0 & 0.25 & 1 & 0.7 \\
0.3 & 0.25 & 0 & 0
\end{array}\right]
$$

It is considered that each DISCO demands $0.1 \mathrm{MW}$ total power from GENCOs as defined by entries in DPM and each GENCO participates in AGC as defined by the following apf:

$$
\begin{aligned}
& a p f_{11}=0.75 \quad a p f_{21}=1-a p f_{11}=0.25 \\
& a p f_{32}=0.5 \quad a p f_{42}=1-a p f_{32}=0.5
\end{aligned}
$$

The total local load in area1=Load of DISCO1 + Load of DISCO2 $=(0.1+0.1)+0.1 \mathrm{pu}=0.3 \mathrm{pu}$

The total local load in area2 $=$ Load of DISCO3 + Load of DISCO $4=0.1+0.1 \mathrm{pu}=0.2 \mathrm{pu}$

The results for this Scenario are given in Fig14-16

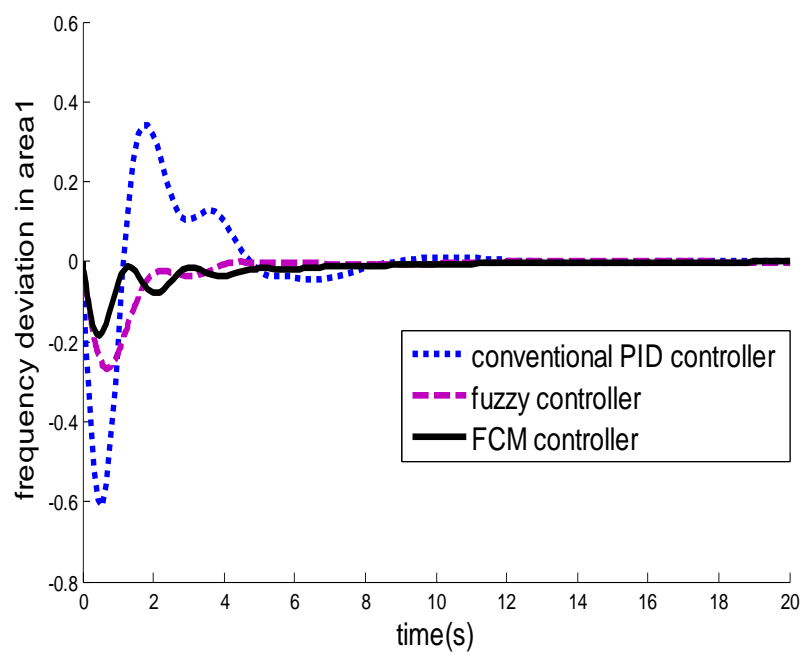

Fig10. Freqency deviation in $\operatorname{area1}(\mathrm{rad} / \mathrm{sec})$

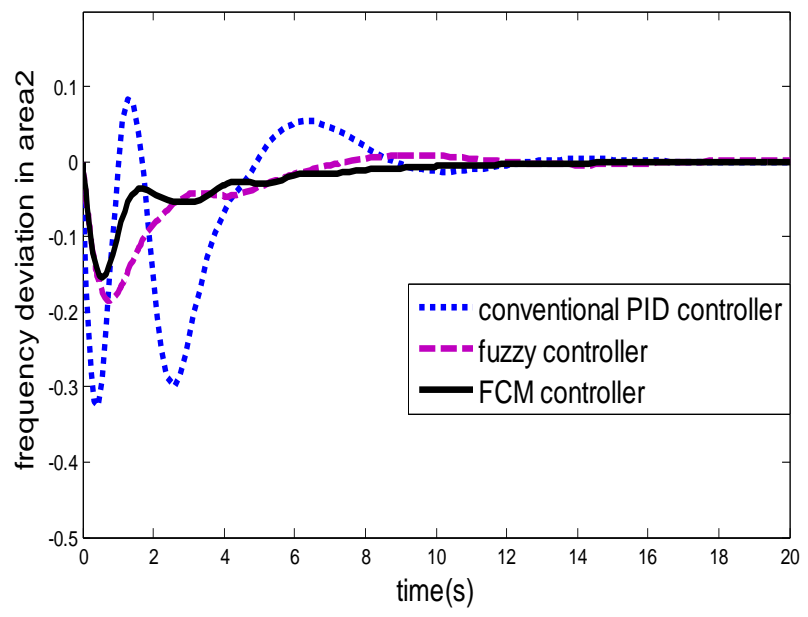

Fig11. Freqency deviation in $\operatorname{area} 2(\mathrm{rad} / \mathrm{sec})$

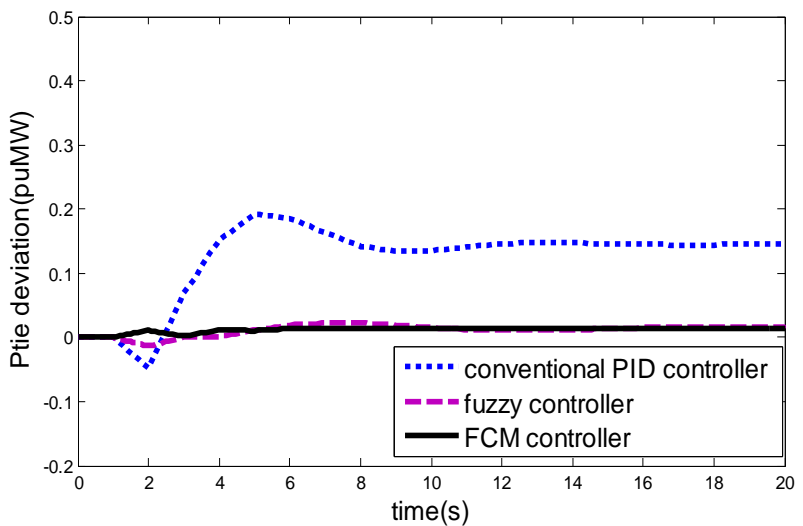

Fig12. Tie line power deviation(pu/MW)

\section{CONCLUSIONS}

In this paper, minimizing rules of fuzzy controller has been proposed to design the FCM controller for the solution of LFC problem in a deregulated power system. Usually, the rule base is determined by experience and control knowledge of human expert which is a trial and error process and takes much time and cost. Thus, to reduce design effort and find optimal fuzzy control rules, the rules are obtained by superimposing the phase plane plot consisting the identified clusters using FCM onto the rule base of the fuzzy controller designed heuristically. The proposed method was applied to load frequency control of twoarea deregulated Power system. The simulation results indicate that the proposed FCM controller can guarantee the stability of the overall system for large parametric uncertainty and maintains same level of performance when compared to Fuzzy controller. The main advantage of the proposed approach is that by reducing the rule base it can significantly reduce the time and effort needed to design a fuzzy controller centered tabs, and so on. For three authors, you may have to improvise.

\section{REFERENCES}

[1] Javad Sadeh, Elyas Rakhshani, "Multi-Area Load Frequency Control in Deregulated Power System using Optimal Output Feedback Method", European Electricity market, 2008, 5th EEE International Conference.

[2] Elyas Rakhshani, Javad Sadeh, "Practical viewpoints on load frequency control problem in a deregulated power system", International Journal on Energy Conversion and management 51 (2010) pp. 1148-1156.

[3] V Donde, A Pai and Hiskens, , "Simulation and Optimization in an AGC System after Deregulation" IEEE Trans on Power Systems, vol 16 no 3,pp481-489,Aug 2001

[4] T. Anil Kumar, N. Venkata Ramana, "Improvement of Dynamic Performance of Three-area Thermal System under Deregulated Environment using HVDC Link", International Journal of Advances in Engineering \& Technology, Sep 2011, ISSN: 2231-1963.

[5] S. Farook, Dr. P. Sangameswara Raju,"Robust Tuning of PID Controller to Optimize Bilateral Contracts in Deregulated Power System using Evolutionary Algorithms", International Journal of Engineering Research and Applications, ISSN: 2248-9622, Vol. 1, Issue 2, pp. 165-172. 
[6] F. Liu, Y.H. Song, J. Ma, Q. Lu, "Optimal Load Frequency Control in the Restructured Power Systems", IEE Proc. Gener. Transm. Distrib., Vol. 15, No. 1, pp.8795, 2003.

[7] Pardeep nain, K.P.Singh patmar, A.K.Singh, "Automatic Generation Control of an Interconnected Power System before and after Deregulation", IJCA Vol-61 no-15 Jan2013

[8] H. Shayeghi, H.A. Shayanfar, A. Jalili, M. Khazaraee, "Area Load Frequency Control Using Fuzzy PID Type Controller in a Restructured Power System", International Conference on Artificial Intelligence, Las Vegas, Nevada, USA, pp. 344-50, June 27-30, 2005.

[9] T.C. Yang, H. Cimon, Q.M. Zhu, "Decentralized LoadFrequency Control Design Based on Structured Singular Values", IEE Proc. Genre. Transm. Dstrib., Vol. 145, No.1, pp. 7-14, January 1998.

[10] H.A. Shayanfar, H. Shayeghi, A. Jalili, M. Sivandian, "A Genetic Algorithm Based AGC of a Restructured Power System", International Conference on Artificial Intelligence, Las Vegas, Nevada, USA, pp. 237-240, June 2006.

[11] A.P. Sakis Meliopoulos, George J. Cokkinides, A.G. Bakirtzis, 'Load-frequency control service in a deregulated environment' Decision Support Systems $24 ; 1999.243-$ 250

[12] H. Shayeghi, H.A. Shayanfar, O.P. Malik, "Robust Decentralized Neural Networks Based LFC in a Deregulated Power System", Electric Power System Research, Vol. 77, No. 3, pp. 241-251, 2007.

[13] A. Chatterjee, G.K. Mahanti, "Comparative Performance of Gravitational Search Algorithm and Modified Particle Swarm Optimization Algorithm for Synthesis of Thinned Scanned Concentric Ring Array Antenna", Progress in Electromagnetics Research B, Vol. 25, pp. 331-348, 2010

[14] E. Rashedi, H. Nezamabadi-pour, S. Saryazdi, "Filter Modeling Using Gravitational Search Algorithm", Engineering Applications of Artificial Intelligence, Vol. 24, No. 1, pp. 117-122, 2010

[15] H. Shayeghi, A. Ghasemi, "Market Based LFC Design Using Artificial Bee Colony", International Journal on

\section{APPENDIX}

Table 3 The Parameters Of GENCOS

\begin{tabular}{|l|l|l|l|l|}
\hline \multirow{2}{*}{$\begin{array}{c}\text { GENCOS } \\
\text { Parameters }\end{array}$} & \multicolumn{2}{|l|}{ Area1 } & \multicolumn{2}{l|}{ Area2 } \\
\cline { 2 - 5 } & GENCO1 & GENCO2 & GENCO3 & GENCO4 \\
\hline Rate $(\mathrm{MW})$ & 1000 & 800 & 1100 & 900 \\
\hline $\mathrm{T}_{\mathrm{T}}(\mathrm{sec})$ & 0.32 & 0.30 & 0.30 & 0.32 \\
\hline $\mathrm{T}_{\mathrm{G}}(\mathrm{sec})$ & 0.06 & 0.08 & 0.06 & 0.07 \\
\hline $\mathrm{R}(\mathrm{Hz} / \mathrm{pu})$ & 2.4 & 2.5 & 2.5 & 2.7 \\
\hline
\end{tabular}

Technical and Physical Problems of Engineering (IJTPE), Issue 6, Vol. 3, No. 1, pp. 1-10, March 2011.

[16] P. Bhatt, R. Roy, S.P. Ghoshal, "Optimized Multi Area AGC Simulation in Restructured Power Systems", Electrical Power and Energy Systems, Vol. 32, pp. 311322, 2010.

[17] T. Hiyama, and Sameshima.T., "Fuzzy Logic Control Scheme for On-Line Stabilization of Multi-Machine Power System", Fuzzy Sets and systems, Vol. 39, pp. 181-194, 1991.

[18] K.A. El-Metwally, "A Fuzzy Logic - Based PID For Power System Stabilization" Electric Power Components and systems, Vol. 29, pp. 659-669, 2001.

[19] Sudha KR, Vijaya Santhi R. Robust decentralized load frequency control of interconnected power system with Generation Rate Constraint using Type-2 fuzzy approach. Int J Electr Power Energy Syst 2011;33:699-707.

[20] Srikanth NV, Vinod Kumar DM. Investigation of stability of fuzzy logic based power system stabilizer using phase-plane analysis. National power systems conference, NPSC; 2004. p. 408-1.

[21] Bezdek JC. Pattern recognition with fuzzy objective function algorithms. NY: Plenum Press; 1981.

[22] Ying H. Deriving analytical input-output relationship for fuzzy controllers using arbitrary input fuzzy sets and Zadeh fuzzy and operator. IEEE Trans Fuzzy Syst 2006;14:654-62

[23] .Sudha K.R, Butchiraju Y, Chandra Sekar A, 'Fuzzy CMeans clustering for robust decentralized load frequency control of interconnected power system with Generation Rate Constraint', International Journal of Electrical Power and Energy Systems (2012), vol.37:1 pp.58-66.

[24] Vakula, V.S.; Sudha, K.R. "Design of differential evolution algorithm-based robust fuzzy logic power system stabiliser using minimum rule base" Generation, Transmission \& Distribution, IET Volume: 6 , Issue: 2, 2012 , pp: $121-132$

[25] Chiu S. Fuzzy model identification based on cluster estimation. J Intel Fuzzy Syst 1994;2:267-78

Table 4 The Parameters Of Control Area

\begin{tabular}{|l|l|l|}
\hline Control area parameters & Area1 & Area2 \\
\hline $\mathrm{K}_{\mathrm{P}}(\mathrm{pu} / \mathrm{Hz})$ & 102 & 102 \\
\hline $\mathrm{T}_{\mathrm{p}}(\mathrm{sec})$ & 20 & 25 \\
\hline $\mathrm{B}(\mathrm{pu} / \mathrm{Hz})$ & 0.425 & 0.396 \\
\hline $\left.\mathrm{T}_{\mathrm{ij}} \mathrm{pu} / \mathrm{Hz}\right)$ & 0.245 & \\
\hline
\end{tabular}

